\title{
THERMOMECHANICAL EFFECTS DURING DIRECT CHILL AND ELECTROMAGNETIC CASTING OF ALUMINUM ALLOYS PART I : EXPERIMENTAL INVESTIGATION
}

\author{
J.-M. Drezet \\ Lausanne, CH-1015 Lausanne, Switzerland \\ M. Plata \\ Alusuisse-Lonza Services Ltd. \\ Research and Development \\ CH-3965 Chippis, Switzerland
}

Laboratoire de Métallurgie Physique, Ecole Polytechnique Fédérale de

\section{$\underline{\text { Abstract }}$}

The deformation and the temperature field evolution within direct chill (DC) and electromagnetic (EM) cast aluminum ingots have been measured in-situ using a simple experimental set-up. The deformation of the cross section of the cold ingots has also been characterized as a function of the casting speed, alloy composition and inoculation condition. The pull-in of the lateral rolling faces has been found to occur in two sequences for $D C$ cast ingots whereas that associated with EMC was continuous. The pull-in was maximum at the center of these faces (about 7-9\%) and strongly depended upon the casting speed. The present results constitute a basis for the validation of the model presented in part II.

\section{Introduction}

During direct chill casting (DCC) (1) or electromagnetic casting (EMC) (2) of large rectangular rolling sheet ingots of aluminum alloys, the metal deforms in different ways. During the start-up phase, butt curl is critical, and special care should be given in controlling the process parameters. In the steady state regime, the solidified shell contracts towards the liquid pool, resulting in a non-rectangular shape of the ingot cross-section ("bone" shape). To compensate for this effect, the corresponding mold sides are designed with convex shapes, usually with two or three linear segments. Figure 1 shows a schematic top view of a typical mold shape used to produce flat rolling ingots.

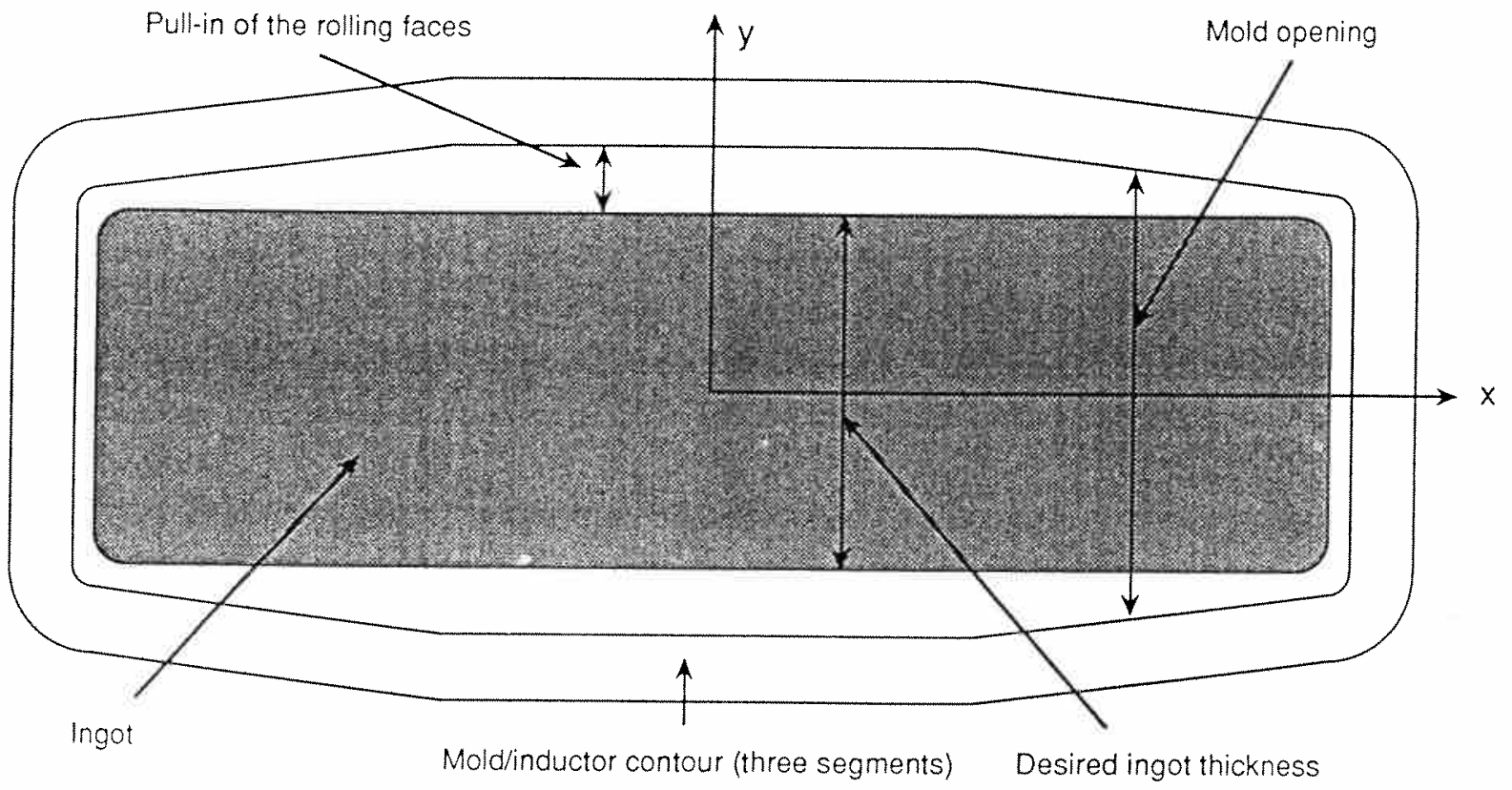

Figure 1: Schematic top view of the mold/inductor shape required to produce fat rolling sheet ingots. 
At present, the mold geometry is designed by trialand-error castings for given alloy, casting speed and ingot size conditions. Therefore, a general understanding of the mechanisms involved in the deformation of the metal is desirable in order to reduce time and costs for designing molds. In this respect, thermo-mechanical calculations of the start-up and of the steady-state regime have become an increasingly used tool $(3,4,5)$. However, due to the many parameters being involved in $\mathrm{DC} / \mathrm{EM}$ casting, these simulations heavily rely on experimental measurements. Besides, the thermomechanical properties of the cast alloys must be known up to, or even above the solidus temperature (6) and the thermal boundary conditions associated with the lateral water jet have to be estimated through inverse modeling techniques (7). Once these values are determined, the results of the simulation must be compared with the experiments. Very often, such a comparison is made only on the "cold "ingot and the deformation during the casting process is not measured.

The purpose of the present study is to describe a simple technique for the in-situ measurement of the deformation and temperature histories during direct chill or electromagnetic casting. In addition to the total deformation of the main body after complete cooling to room temperature, the steady-state temperature profile of the metal during casting, the corresponding shape and depth of the melt pool ("sump") and the contraction of the solidified shell inside the mold/inductor have been measured. The influence of the casting speed, of the alloy composition, of the grain refinement and of the air gap formation during $\mathrm{DC}$ casting on the deformation of the ingot has been investigated. After analyzing the experimental results, the main mechanisms involved in the deformation of cast ingots are discussed. These results constitute the basis for the numerical simulations presented in Part II.

\section{Experimental procedure}

The DCC and EMC trials were carried out with a fully automated casting machine including metal level control system. The nominal ingot cross section was $1860 \times 510 \mathrm{~mm}$ for the DCC trials and $1800 \times 500 \mathrm{~mm}$ for the EMC trials; the cast height was typically 3 to 4 $\mathrm{m}$. Casting parameters such as water cooling flow rate and metal distribution bags were kept constant for every combination of alloy and casting speed. A standard $35^{\circ}$ bottom block as described by Carrupt and
Moulin (8) and a pulsed water cooling technique during the starting phase were employed for all the experiments.

The DC mold lateral side was made out of three straight lines as shown in figure 1 . The inductor used for the EMC trials was designed to produce $500 \mathrm{~mm}$ thickness sheet ingots. The liquid metal was maintained at a distance of $6 \mathrm{~mm}$ from the screen. The inductor current was $6 \mathrm{kA}, 2500 \mathrm{~Hz}$. The inductor and screen were also made out of three straight lines along the rolling faces of the ingot.

Three aluminum alloys were cast with the compositions given in Table I. The grain refiner was the titanium boron aluminum alloy, Al-Ti 5wtpct-B 2 wtpct.

\section{Deformation measurement after cooling}

After complete solidification and cooling of the ingot in the pit, it was reintroduced through the mold/inductor and the lateral contraction of the ingot was measured at several points of the ingot rolling face and for different heights: in the butt zone, at mid-height (at least 2 meters from the butt in order to ensure nearly steady-state conditions) and in the upper part (head) of the casting.

\section{Sump depth and cooling curves measurements}

Figure 2a shows the experimental set-up used to determine the sump depth. This measurement was made at $85 \mathrm{~cm}$ from the short side of the casting. A set of five thermocouples attached to the end of stainless steel rods was introduced into the metal during casting after a steady-state regime was reached. The last rod was submerged along the center line of the ingot and the first one was near to the lateral surface. In order to make sure that the five rods "disappeared" at the constant withdrawal speed in the liquid pool, they were pulled downwards by two non-instrumented guiding rods,

\begin{tabular}{|c|c|c|c|c|}
\hline Alloy & $\mathrm{Fe}$ & $\mathrm{Si}$ & $\mathrm{Mg}$ & $\mathrm{Mn}$ \\
\hline AA1 $\times \mathrm{x} x$ & 0.41 & 0.14 & 0.012 & 0.018 \\
\hline AA3 $\times x \times$ & 0.46 & 0.22 & 1.14 & 1.04 \\
\hline AA5 $\times x \times$ & 0.24 & 0.18 & 2.75 & 0.27 \\
\hline
\end{tabular}

Table I: Composition (wtpct) of the three aluminum alloys. 
previously introduced into the metal. During their descent, the rods were guided through a specially designed rail (see diagram on figure $2 a$ ). The thermocouples (type $K$ ) were linked to a data-logger and the five temperatures were recorded every 0.1 second. This method allowed the sump depth to be calculated by considering the end of solidification measured by the thermocouple placed at the center line of the casting. Such measurements also gave the temperature profile in the solid part of the ingot and the shape of the solidification front during the steady-state casting regime.

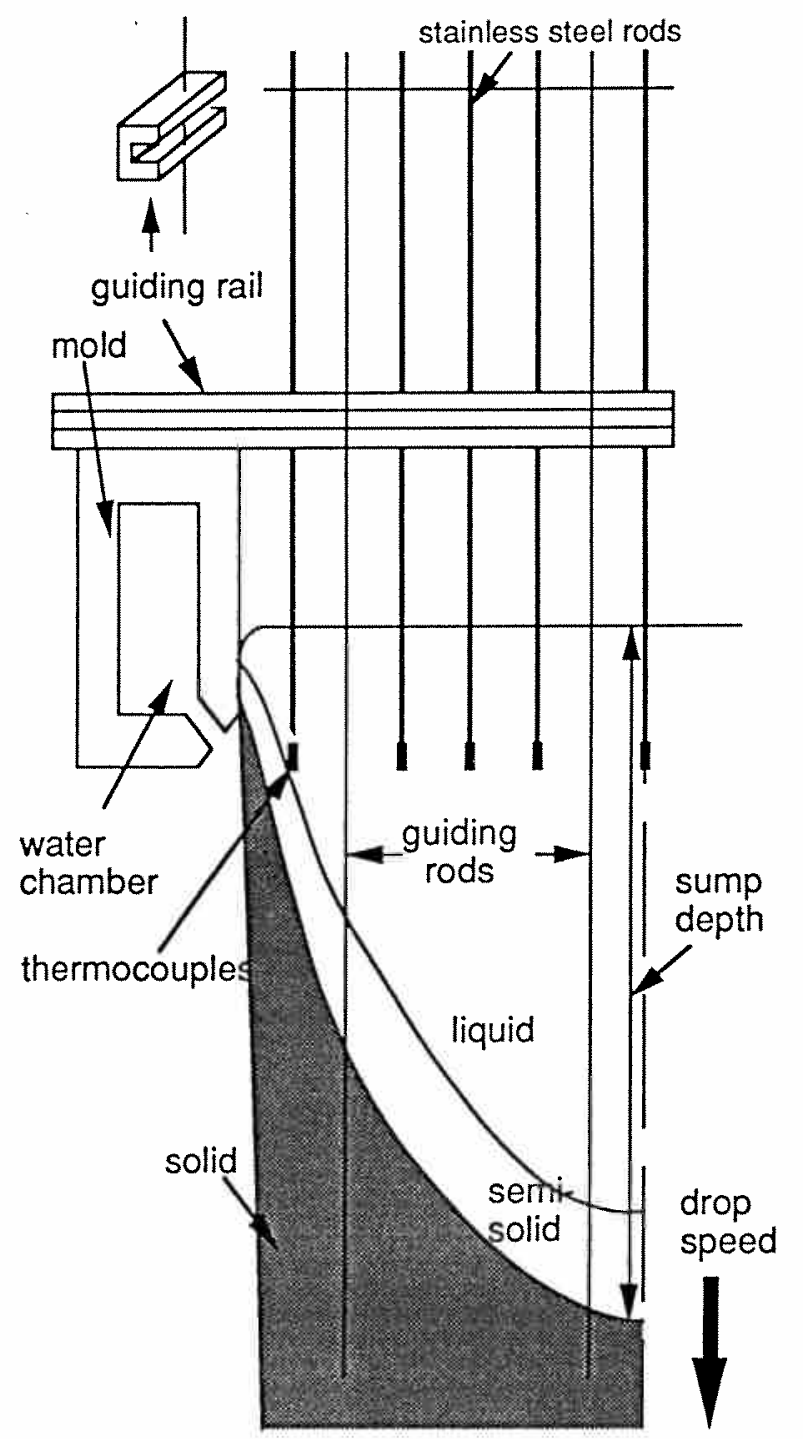

Figure 2a: Experimental set-up for the measurements of the temperature profile and sump depth.

\section{In-situ measurement of the air gap}

Figure 2b shows the experimental set-up used to measure the gap distance between the metal and the mold/inductor during the steady-state of the process. This set-up was located $85 \mathrm{~cm}$ from the other short side of the ingot. A quartz rod carrying two thermocouples was introduced into the liquid pool. The rod was free to move downwards through a guiding cylinder and at the same time, it was also free to move along the stand by translation of the cylinder on two guiding rails. The quartz rod first dropped into the liquid under its own weight and its extremity was then "swallowed" by the

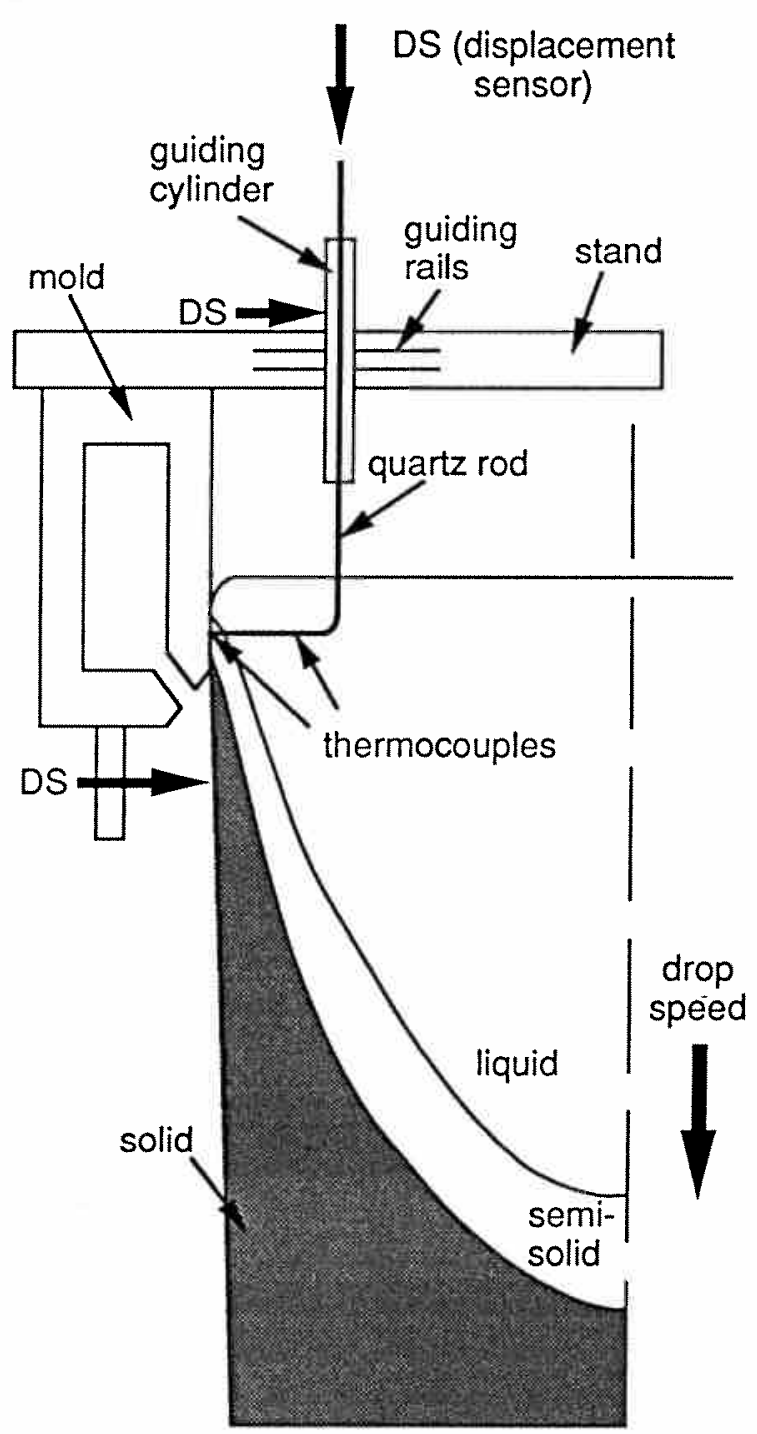

Figure 2b: Experimental set-up for the in-situ measurement of the casting displacement in the mold/inductor. 
mushy zone. From that instant, the quartz rod moved downwards at the casting speed of the ingot. When the solidifying metal shell pulled away from the mold surface, the rod followed and its lateral and vertical displacements were recorded by two sensors. The two thermocouples inserted into the quartz rod measured the temperatures at two locations near to the ingot surface (see figure $2 \mathrm{~b}$ ). These data permitted to assess more precisely the shape of the mushy zone near the mold wall. In order to test the accuracy of this simple set-up, the contraction measured at the exit of the mold/inductor was compared with the value given by a displacement sensor, which was attached to the bottom of the mold/inductor. It is to be noted that the two thermocouples wires were not soldered together since they were directly immersed into the molten aluminum. Thus, the time of entrance of the rod into the liquid pool could be determined accurately from the time of electrical contact.

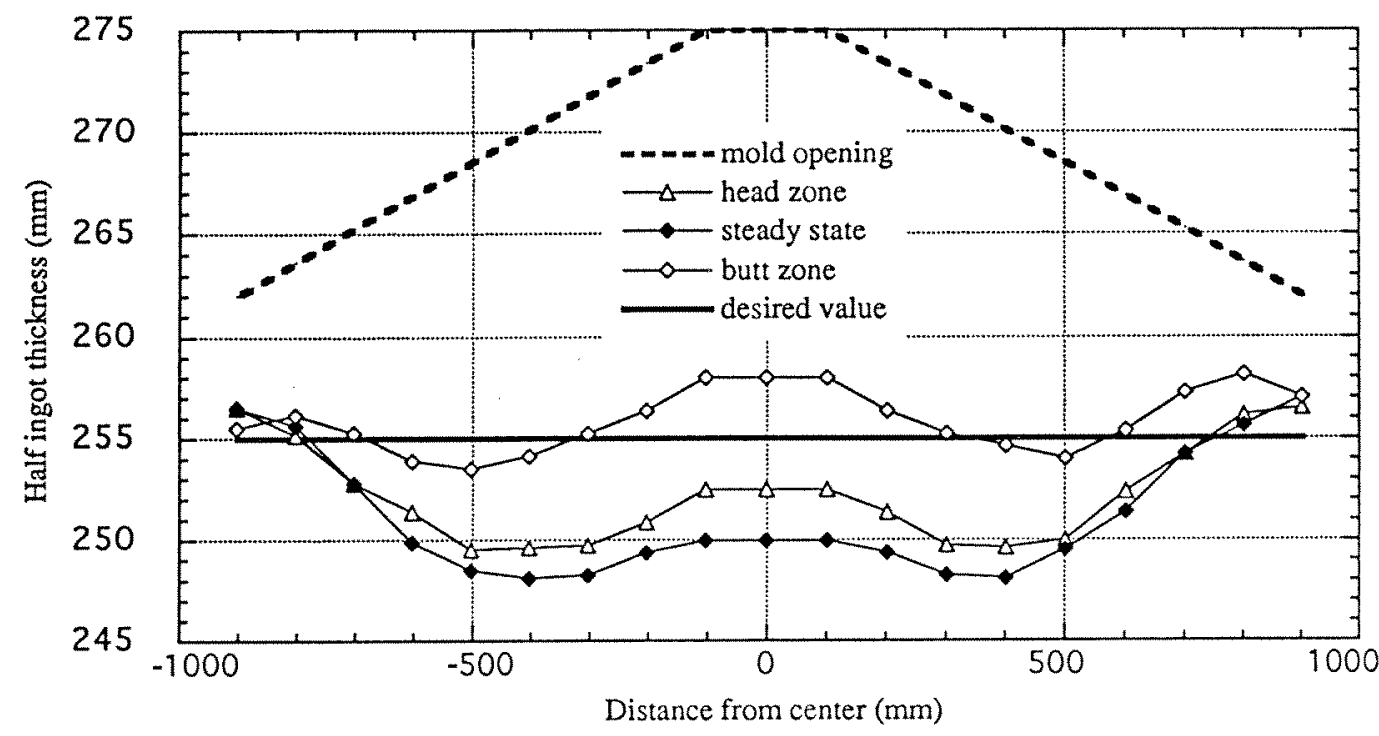

Figure 3: Contraction of a 3xxx DC-cast ingot in the starting (butt zone), stationary and end (head zone) phases and geometry of the mold (casting speed: $70 \mathrm{~mm} / \mathrm{min}$, nominal size: $1860 \times 510 \mathrm{~mm}$ ).

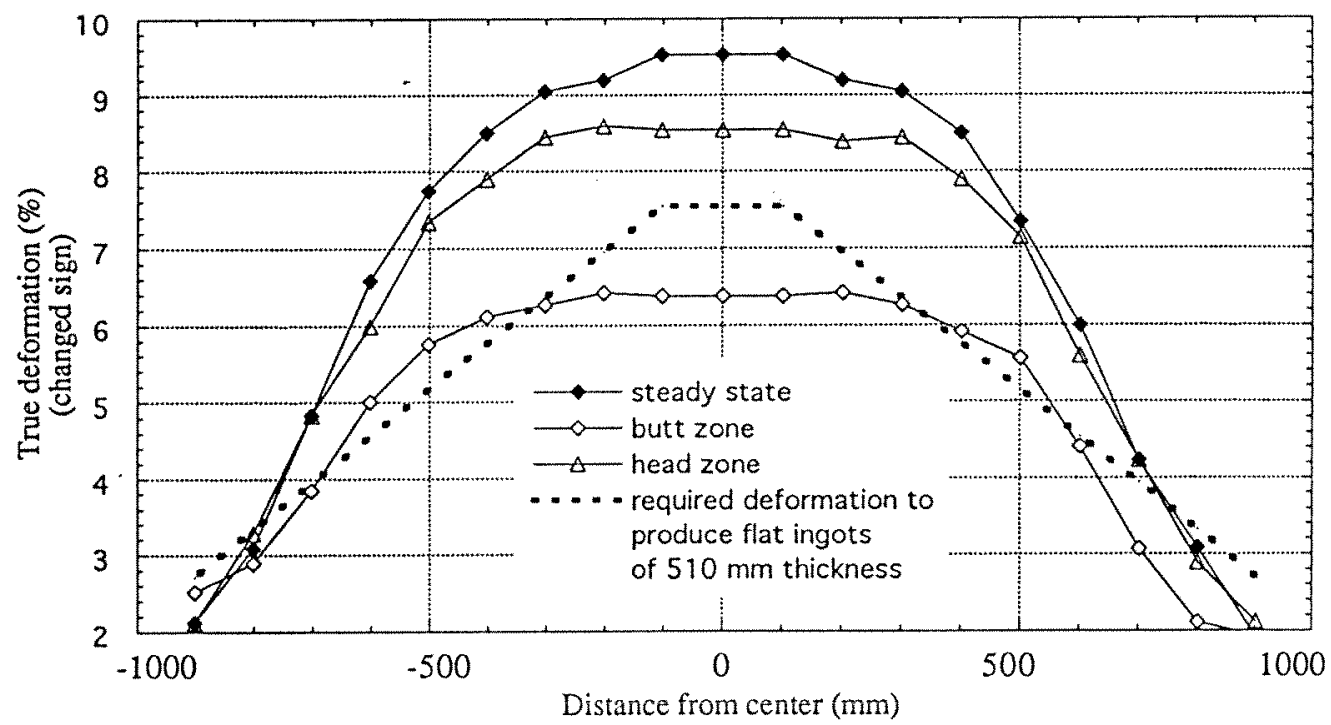

Figure 4: True deformation (with opposite sign) of the $3 \times x \times$ ingot cast at $70 \mathrm{~mm} / \mathrm{min}$ as deduced from figure 3 . 


\section{Deformation of the cold ingot}

The three measured cross-section profiles shown in figure 3 have been obtained for a $3 \times x \times$ DC ingot cast at $70 \mathrm{~mm} / \mathrm{min}$. These profiles have been measured after complete cooling at three different heights of the ingot and the interior mold shape is also represented for comparison. After a transient stage of about one meter, the cross section shape remains nearly constant : this corresponds to a nearly stationary thermo-mechanical stage. Near the top of the ingot (head), the section change of the ingot becomes less pronounced as is the case of the start-up stage. Figure 3 clearly shows that the rolling faces pull-in is important : about $25 \mathrm{~mm}$ for the half ingot thickness at the center of the ingot in the steady-state casting regime. The contraction of the ingot near the two short sides remains nearly constant during the entire casting process. The horizontal line at $255 \mathrm{~mm}$ indicates the desired half thickness of a perfectly flat ingot. This value, which is somehow arbitrary, is fixed to a value close to the final thickness of the short sides.

The true deformation (logarithmic strain) of the ingot was then calculated and is shown with the opposite sign in figure 4 . In the steady-state regime of the casting, the metal contraction is about $9.5 \%$ in the central part of the rolling faces but only about $2.5 \%$

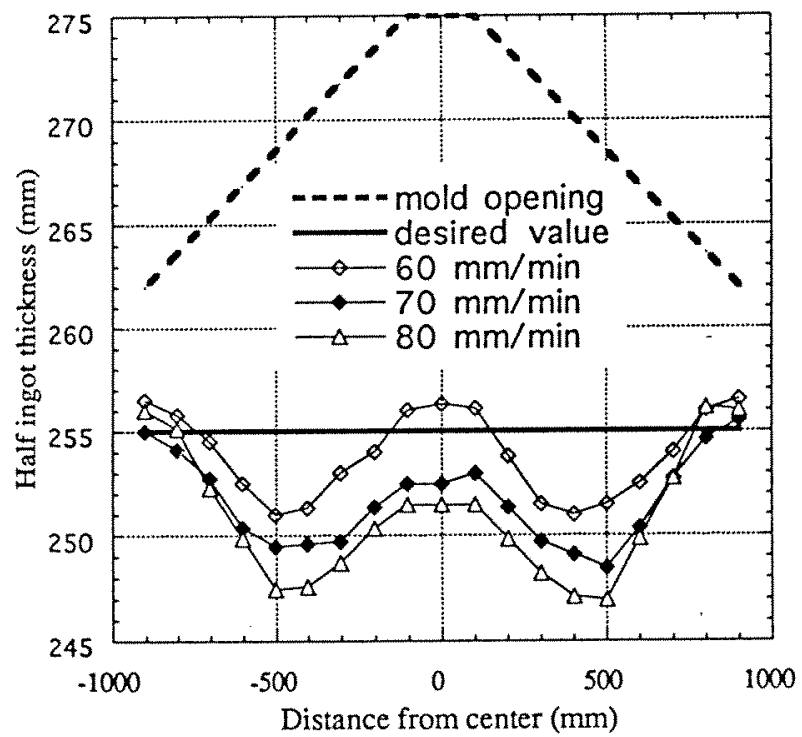

Figure 5: Influence of the casting speed on the ingot contraction for the alloy $1 \mathrm{xxx}$ in the steady-state regime. near the short sides. The required deformation to produce a perfect flat ingot of $510 \mathrm{~mm}$ thickness with this mold geometry is also shown for comparison. The contraction near the short sides is slightly less than the desired value, thus leading to a thickness which is slightly larger than expected. At the opposite, the ingot contracts too much in the center when a stationary regime is obtained.

In order to better understand the mechanisms responsible for the deformation of the ingot during semicontinuous DC-casting process, the contraction in the steady-state regime of the process was measured for various casting conditions and alloy compositions. The influence of the casting speed on the deformation of the ingot in the stationary regime of casting for the alloys $1 \times x x$ and $3 x x x$ is shown in figure 5 and 6 , respectively. For both alloys, it is apparent that the pull-in of the rolling faces center increases with the withdrawal speed whereas the ends of these faces are almost unaffected by the casting speed.

The influence of the alloy composition and grain refinement on the steady-state deformation is shown in figure 7 , for a casting speed of $60 \mathrm{~mm} / \mathrm{min}$. The three alloys were grain refined just before casting with $50 \mathrm{ppm}$ of AlTi5B2 ; the case of the non-grain refined alloy $1 \mathrm{xxx}$ is also shown in this figure. As can be seen, the ingot contraction is not significantly affected by the microstructure: all the measurements fall in a narrow

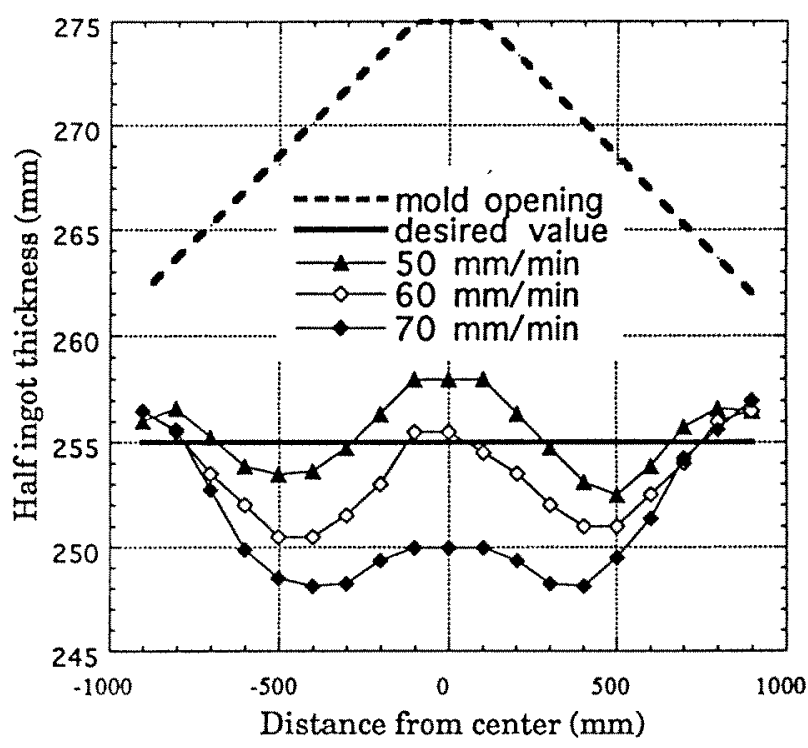

Figure 6: Influence of the casting speed on the ingot contraction for the alloy $3 x x x$ in the steady-state regime. 
band within the typical error of $1 \mathrm{~mm}$. As for the influence of the casting speed, the alloy composition does not appear to affect the level of contraction near the short sides of the ingot.

The measurement of the EM-cast ingot crosssection is shown in figure 8 for the alloy $3 \times x x$ cast at 65 $\mathrm{mm} / \mathrm{min}$. The profile of the electromagnetic screen and the estimated position of the liquid meniscus are also plotted. The shape of the liquid free surface is simply given by subtracting the estimated gap (about $6 \mathrm{~mm}$ ) from the position of the magnetic screen and neglecting the radius of curvature at the ingot corners (2). The maximum pull-in in the steady-state regime appears again at the center of the rolling faces and is about 17 $\mathrm{mm}$, which represents a contraction of $7 \%$ with respect to the estimated free liquid lateral surface. Near the short sides of the ingot, the contraction seems to be larger than in DC casting (11 $\mathrm{mm}$ in figure 8). However, due to the radius of curvature of the liquid meniscus at the ingot corners, the effective contraction with respect to the free liquid surface is only about $7 \mathrm{~mm}$. This value is close to that measured for the DC cast ingot shown in figure 3.

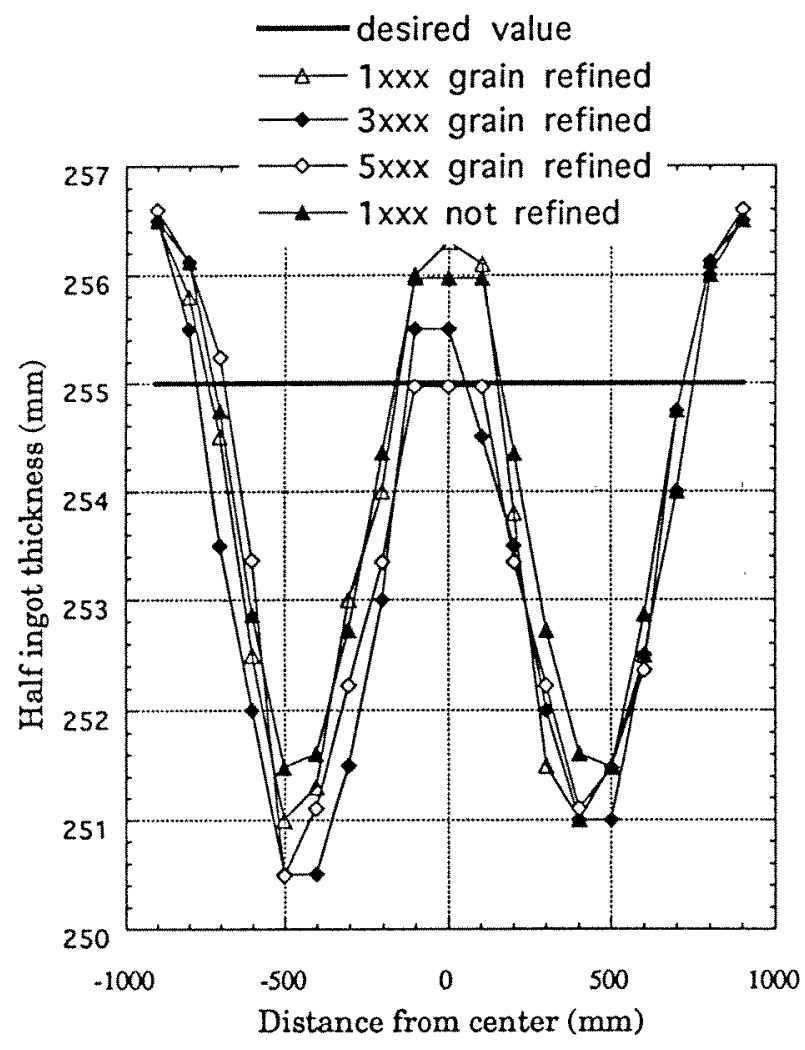

Figure 7: Influence of the alloy composition and inoculation conditions on the ingot contraction (casting speed: $60 \mathrm{~mm} / \mathrm{min}$ )

\section{Temperature profile and sump depth}

Figure 9 shows the cooling curves recorded during the $\mathrm{DC}$ casting of a $1 \mathrm{xxx}$ ingot cast at $80 \mathrm{~mm} / \mathrm{min}$. The position of the thermocouples from the surface of the ingot is indicated on the figure. Using the withdrawal speed of the ingot, the time scale on the horizontal axis has been converted into the distance from the top surface of the liquid metal. From these measurements, it is apparent that the liquid pool is approximately uniform in temperature (about $665^{\circ} \mathrm{C}$ ). The temperature at each thermocouple location starts to decrease significantly as soon as the metal begins to solidify. Figure 10 shows the steady-state temperature profile within the $1 \times x x$ ingot during DC casting and the sump depth as determined from the five temperature histories of figure 9 . For the alloy $1 \times x x$ used in the present investigation, the values of $656^{\circ} \mathrm{C}$ and of $632^{\circ} \mathrm{C}$ for the liquidus and solidus temperatures respectively were determined by Gabathuler (9) by means of thermoanalysis (for conditions close to those of the DC casting). These values, which are also indicated in figure 9 by two horizontal lines, were used to evaluate the sump depth. The deep sump depth shown in figure 10 $(580 \mathrm{~mm}$ ) is due to the high casting speed used for this particular ingot, lower casting speeds resulting in shallower sumps (see Table II).

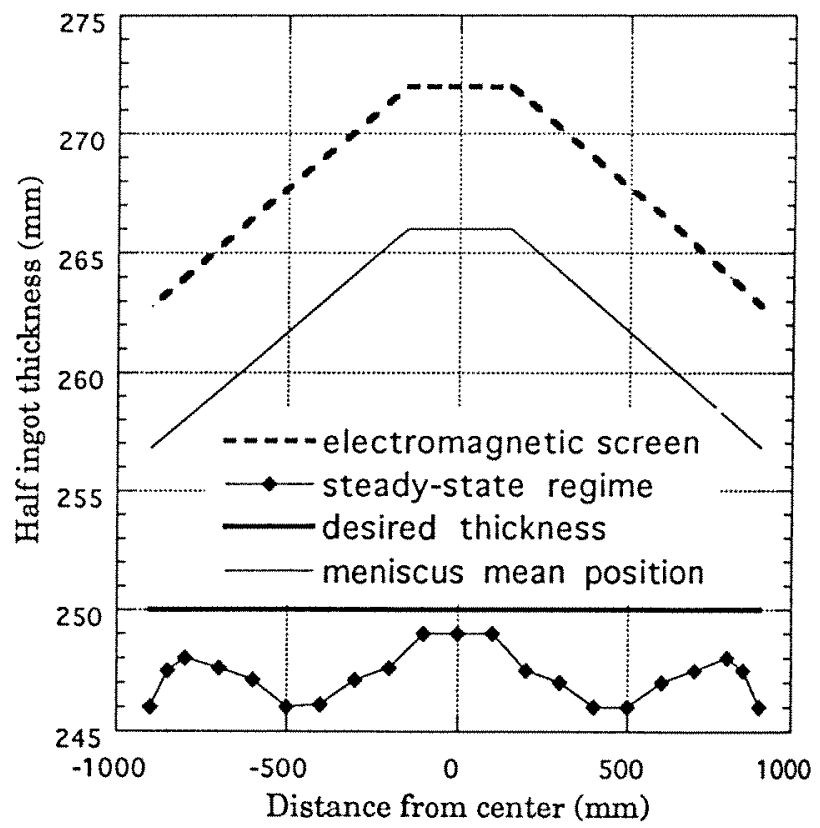

Figure 8: Contraction of a $3 \times x x$ EM-cast ingot in the stationary phase, geometry of the screen and estimated position of the meniscus (casting speed: $65 \mathrm{~mm} / \mathrm{min}$, nominal size: $1800 \times 500 \mathrm{~mm}$ ). 


\section{Contraction of the solidifying shell}

The recorded temperatures and contraction of the solidifying shell in the mold are shown in figure 11 for the alloy $5 \times x \times$ DC cast at $60 \mathrm{~mm} / \mathrm{min}$. These data are again represented as a function of the distance below the top liquid surface, as measured by the vertical displacement sensor. They have been measured after a nearly steadystate regime had been reached. These temperatures were recorded at the surface and at $50 \mathrm{~mm}$ from the ingot surface. As can be seen, the initial height where the metal and the mold are in good thermal contact is about $30 \mathrm{~mm}$ (zone $\mathrm{A}$ in figure 11). Then, an air gap forms over a distance of $25 \mathrm{~mm}$ (zone B) and remains at a constant clearance of $1.5 \mathrm{~mm}$ for the next $20 \mathrm{~mm}$ (zone C). After this short plateau, the metal pulls away from the mold at a nearly constant rate (zone D). The displacement of the ingot measured by this moving quartz rod was checked at the exit of the mold with the value recorded by the displacement sensor which was attached below the mold (figure $2 \mathrm{~b}$ ).

The point of impact of the cooling water on the lateral side of the ingot is shown in figure 11. It almost coincides with the end of the constant air gap zone. The

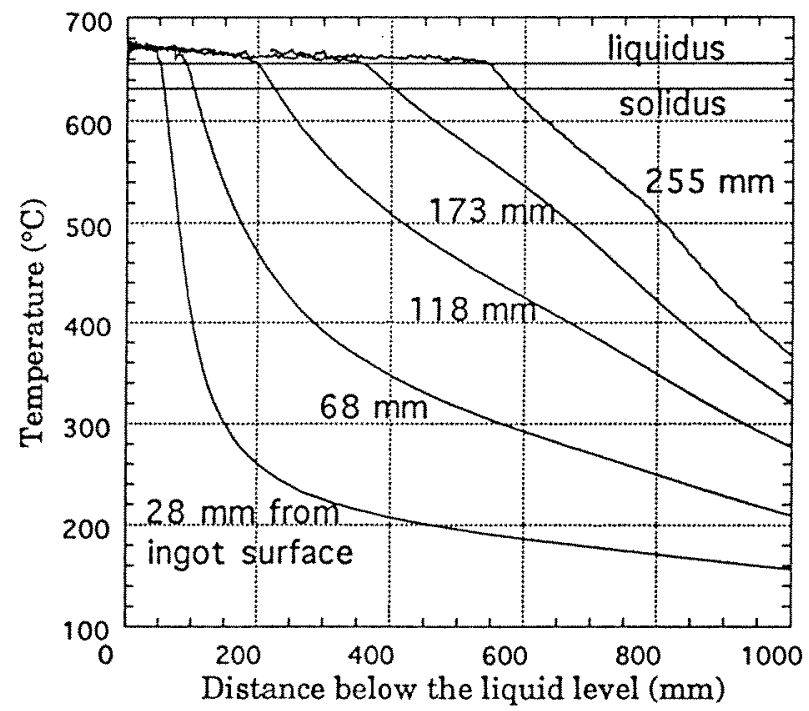

Figure 9: Measured temperatures during DC casting of a $1 \mathrm{xxx}$ alloy (casting speed: $80 \mathrm{~mm} / \mathrm{min}$ )

\begin{tabular}{|c|c|c|c|}
\hline Drop speed & $50 \mathrm{~mm} / \mathrm{min}$ & $60 \mathrm{~mm} / \mathrm{min}$ & $80 \mathrm{~mm} / \mathrm{min}$ \\
\hline Sump depth & $425 \mathrm{~mm}$ & $480 \mathrm{~mm}$ & $580 \mathrm{~mm}$ \\
\hline
\end{tabular}

Table II: Sump depth for the alloy $1 \times x \times$ and different casting speeds (nominal size $1860 \times 510 \mathrm{~mm}$ ). surface temperature of the ingot just below the cooling water spray is about $200^{\circ} \mathrm{C}$.

As can be seen in figure 11, the surface temperature of the ingot during the contact period $A$ is already below the liquidus of the alloy whereas, at 50 $\mathrm{mm}$ from the surface of the metal, the metal is still totally liquid. Although the temperature measured at the surface of the ingot might be slightly biased by an incomplete wetting of the thermocouple, it increases slightly (about $10^{\circ} \mathrm{C}$ ) at the onset of the air gap formation (beginning of zone $B$ in figure 11) when the heat extraction is decreased. At the temperature of $620^{\circ} \mathrm{C}$ measured at the surface of the $5 \mathrm{xxx}$ alloy ingot when it pulls away from the mold, the volume fraction of solid is estimated to be about $70 \%$ according to Gabathuler (9). Clearly, the metal contraction in the mold occurs when the alloy is still in the semi-solid state.

Figure 12 shows the recorded temperatures and displacement of the solidifying shell during the steadystate EM casting regime of an alloy $5 \mathrm{xxx}$ cast at 66

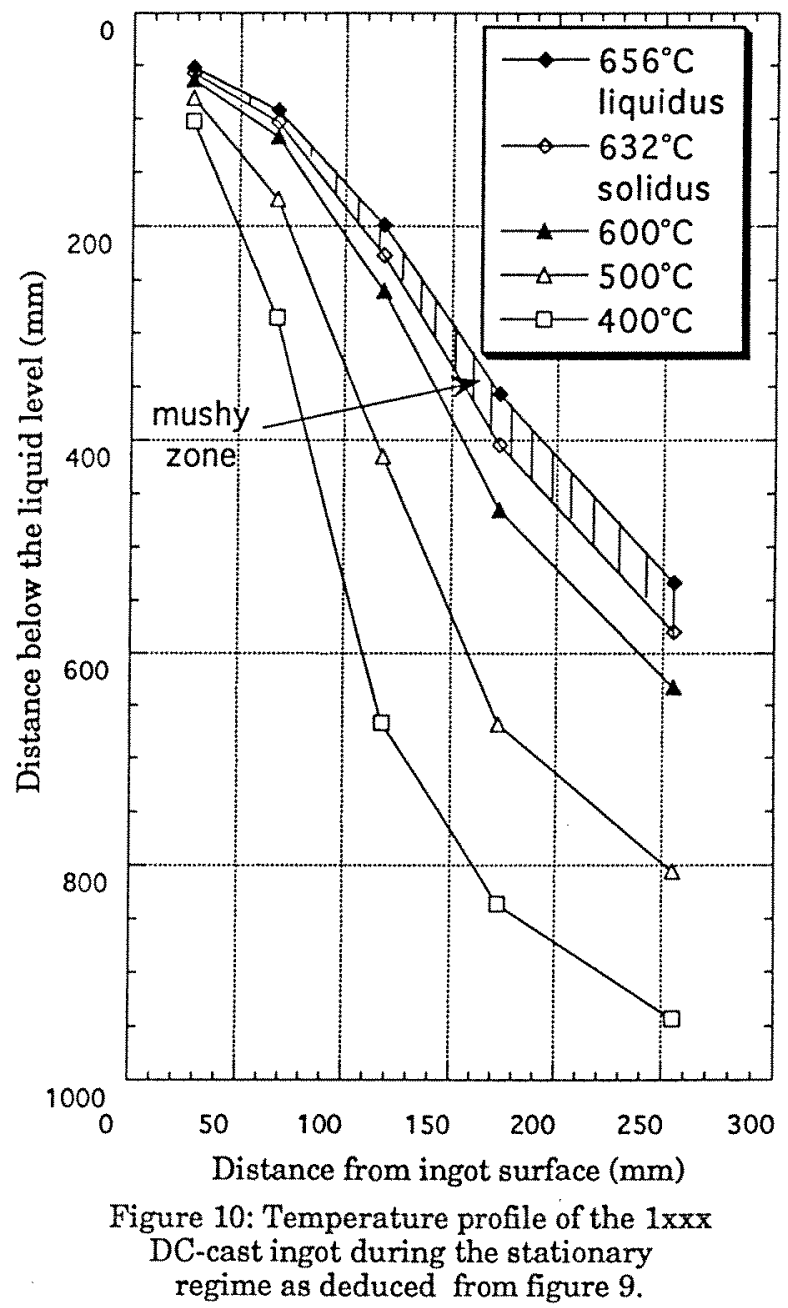


$\mathrm{mm} / \mathrm{min}$. The displacement plateau observed in DC casting (zone $\mathrm{C}$ in figure 11) is no longer present and the contraction of the shell just below the point of impact of the cooling water occurs at nearly constant rate. At 250 $\mathrm{mm}$ below the top liquid surface, the rolling face pull-in is almost $10 \mathrm{~mm}$. The two temperatures within the EMC ingot were recorded at the lateral surface and at $40 \mathrm{~mm}$ from the surface. The surface temperature at the point of impact of the water cooling is about $200^{\circ} \mathrm{C}$ as was already the case for the DCC process. Above this point, the temperature within the liquid near the surface is much more uniform than in DC casting due to firstly, the absence of a direct contact with a mold and secondly, the strong convection induced by the electromagnetic field (10).

\section{Discussion}

Weaver $(11,12)$ has explained the ingot deformation occurring during semi-continuous casting in terms of the extension of the liquid pool and of the shape of the solid shell. This model is based on the hypothesis that the heat extraction is uniform and horizontal. As seen in figure 10 , this is clearly not the case. Moreover, the model of Weaver requires numerous casting trials for the estimation of alloy-dependent constants. The present experimental investigation, in particular the insitu measurements of the temperature field and of the surface pull-in of the rolling faces, allows to assess more clearly the main mechanisms leading to the non-uniform contraction of the ingot during DC/EM casting.
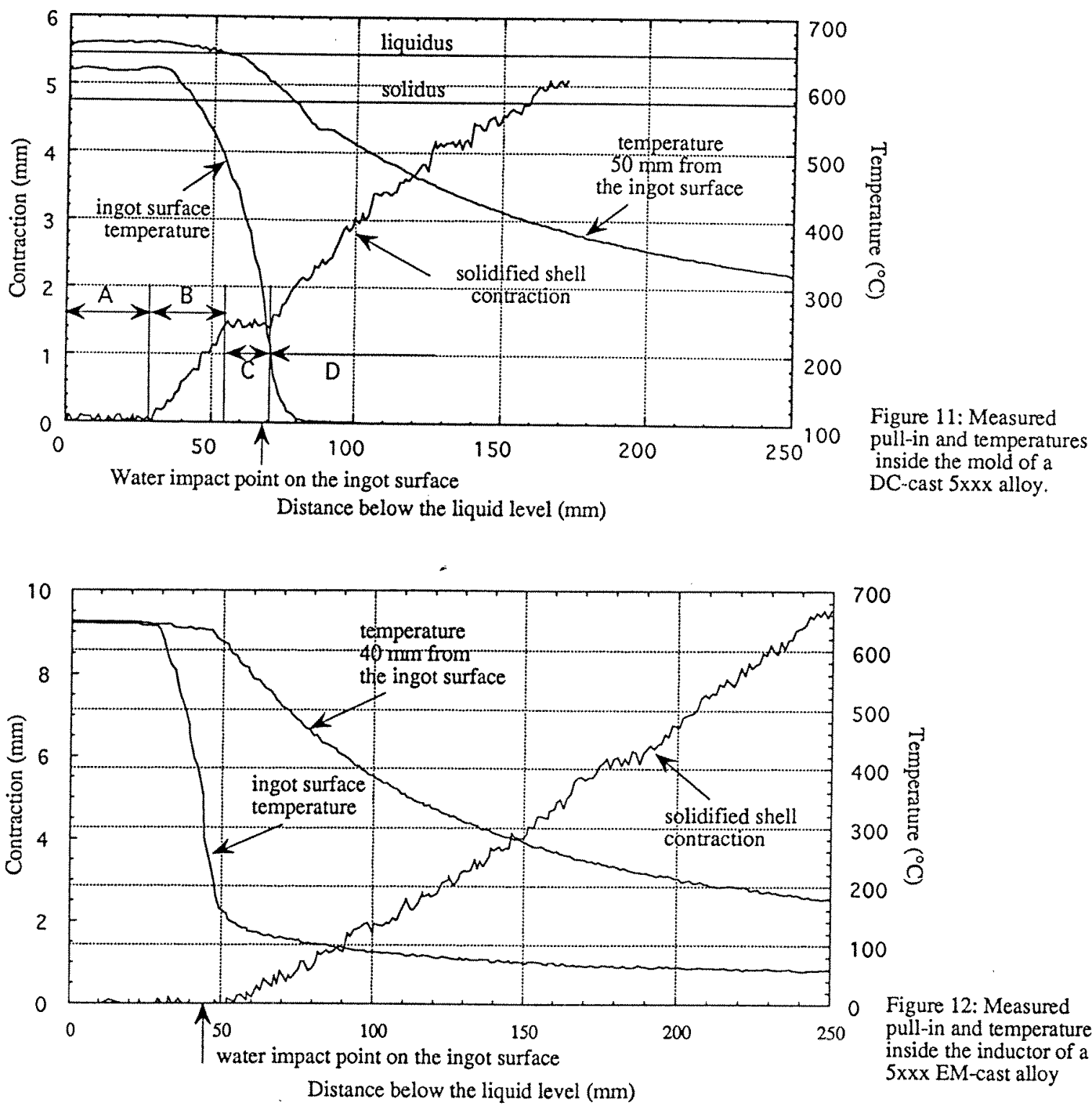

700

600

500

400

300

200

100

Figure 12: Measured pull-in and temperatures inside the inductor of a 5xxx EM-cast alloy 


\section{Contraction of the metal during solidification}

During solidification of a metal, there are essentially two contributions to the ingot contraction, the first one being associated with the phase change (about 6.5\% in volume for aluminum (13) and the second contribution arising from the solid state thermal contraction during subsequent cooling (about 1.5\%). During the liquid-to-solid phase transformation, there is a constant liquid feeding within the mushy zone to compensate for the density variation. For an aluminum4.5 wtpct copper alloy, it has been shown that the associated pressure drop within the liquid is not more than one tenth of the atmospheric pressure when no microporosity forms (14). For alloys having an even larger solidification interval (e.g., Al-Mg), feeding is more difficult and as a result, microporosity may develop more easily. Micrographs of the as-cast ingots revealed almost no microporosity. In any case, the pressure drop of the liquid within the mushy zone induced by the density change between the liquid and solid phases is certainly too low to explain the section change of the cast ingots. Considering figure 11, for example, it is seen that the initial pull-in (up to the plateau labeled "C") only represents $1.5 \mathrm{~mm}$ (i.e., $0.6 \%$ ) of contraction. At the end of this plateau (i.e., $70 \mathrm{~mm}$ below the top liquid surface), the surface is totally solid and the solidus line is already 30 to $40 \mathrm{~mm}$ in the interior of the ingot (see figure 10). Thus, the solid skin of the ingot is already well developed and cannot be deformed by the pressure drop of the liquid within the mushy zone.

The $9.5 \%$ pull-in measured at the ingot center during DC casting or the $7 \%$ pull-in measured during EM casting after complete cooling is therefore a consequence of the deformation of the solid ingot. Although thermal contraction is only $1.5 \%$ for a uniform temperature specimen, the cumulated deformation and associated bending during continuous casting can explain the large pull-in of the rolling faces. Such a mechanism, which is supported by the transient deformation state near the bottom of the ingot (see figure 3 ), is detailed hereafter.

\section{Inward pull-in of the rolling faces}

During cooling, the metal experiences a high nonuniform thermal gradient (see figure 10) which gives rise to differential thermal contraction and high stresses that can be partially relieved by creep. During DC casting, the alloy undergoes two different coolings, the first one when it is in direct contact with the mold and the second one under the cooling water spray. This leads to the appearance of a thin solid shell in between the two cooling zones and nearly parallel to the mold. This thin shell contracts under the high local thermal gradient (figure 11), the metallostatic pressure being negligible. On the contrary, during EM casting, the metal experiences only one cooling, the water spray, and the deformation is continuous (figure 12). However, at about $100 \mathrm{~mm}$ below the top liquid surface, the contraction is about the same in both processes $(2.5 \mathrm{~mm}$ or $1 \%$ deformation). At this height, the solid skin is already well developed and extends beyond the second thermocouple attached to the quartz rod, i.e., the surface skin is at least 40 to $50 \mathrm{~mm}$ thick in both DC and EMC casting. Such a skin continues to thicken and deform during further cooling of the casting.

The calculation of butt curl and swell during the start-up phase of DC casting has already been performed by several authors $(3,4,5)$. A similar calculation, which requires a precise knowledge of the boundary conditions and of the thermomechanical properties of the alloy, has been carried out for the pullin of the rolling faces; the results of these simulations are presented in part II.

\section{Conclusion}

The ingot deformation during $\mathrm{DC} / \mathrm{EM}$ casting has been measured in-situ in order to elucidate the mechanisms responsible for the large and non-uniform contraction of the ingot cross-section. It appears that the air-gap formation in DC casting is only $0.5 \%$ near the center of the rolling faces, whereas the total deformation after complete cooling of the ingot is about $9 \%$. This rules out any influence of the solidification shrinkage. Thus it is concluded that the pull-in of the faces is due only to the thermal stresses which develop upon cooling of the ingot. Although linear thermal contraction is only $1.5 \%$ in aluminum alloys, the horizontal component of the temperature gradient introduces a bending of the ingot.

The prediction of the ingot deformation for a given $\mathrm{mold} /$ inductor bow would allow to optimize the design of a mold/inductor capable of producing flat ingots. This problem requires to use a three dimensional model which adequately takes into account the shape of the sump profile, the edge reinforcement and the viscoelastic 
behavior of the alloy. Numerical simulations are presented in Part II.

\section{Acknowledgment}

The financial support of the swiss Commission pour l'Encouragement de la Recherche Scientifique (CERS), under grant 2496.1, is greatly acknowledged.

\section{References}

1. E.F. Emley: Continuous casting of aluminum; International metals reviews, June 1976.

2. Y. Krähenbühl, R. Von Kaenel, B. Carrupt, J.C. Weber: Understanding the starting phase: a key factor to the success of EMC (electromagnetic casting); Light metals, 1990, p. 893.

3. H. Fjaer and A. Mo: Alspen-a mathematical model for thermal stresses in direct chill casting of aluminum billets, Met. Trans, vol. 21B, 1990, p.1049.

4. S. Mariaux, M. Rappaz, Y. Krähenbühl, M. Plata: Modeling of thermo-mechanical effects during the start-up phase of the electromagnetic casting process, Light Metals, 1992, p.175.

5. B. Hannart, F. Cialti, R. V. Schalkwijk: Thermal stresses in DC casting of aluminum slabs: application of a finite element model, Light Metals, 1994, p.879.

6. J.M. Drezet and G. Eggeler: High apparent creep activation energies in mushy zone microstructures, Scriota Met. et Mater, vol. 31, Sept. 1994, p. 757.

7. J.V. Beck, B. Blackwell, J.R. St Clair: Inverse Heat Conduction, Wiley Interscience, J. Wiley \& Sons, 1985.
8. B. Carrupt and C. Moulin: Effects of casting technology and bottom block design on butt curl formation with rolling slabs, $8^{\text {th }}$ International Sheet and Plate Conference, Louisville, Kentucky, 5-8 Oct. 1993.

9. J.P. Gabathuler : Thermoanalyse, Alusuisse internal technical report, June 1985.

10. O. Besson, J. Bourgeois, P.A. Chevalier, J. Rappaz and $R$. Touzani : Numerical modeling of electromagnetic casting processes, Journal of computational physics, Vol.92, No.2, 1991, p.482.

11. C.H. Weaver: An empirical model to explain crosssection changes of D.C. sheet ingot during casting, TMS, AIME, 1976, p.441.

12. C.H. Weaver: Designing sheet ingot molds to produce rectangular ingots of the desired thickness and width, Light Metals, 1991, p.953.

13. L.F. Mondolfo : Aluminum alloys: structure and properties, Boston: Butterworths, 1976.

14. J. Ampuero, A. F. A. Hoadley and M. Rappaz : Numerical and experimental study of microporosity evolution during the solidification of metallic alloys, Modeling of Casting. Welding and Advanced Solidification Processes $V$, edited by $M$. Rappaz, M. R. Ozgu and K. W. Mahin, TMS, 1991, p.449. 